Viktor Reutskyy ${ }^{1}$, Oleksandr Ivashchuk ${ }^{1}$, Sergiy Mudryy ${ }^{1}$ and Nataliya Mitina ${ }^{2}$

\title{
CYCLOHEXANE OXIDATION IN THE PRESENCE OF COBALT CHELATES
}

\author{
'Departament of Technology of Organic Products, Lviv Polytechnic National University \\ 12, Bandera str., 79013 Lviv, Ukraine; ivaschuk@polynet.Iviv.ua \\ 2Departament of Organic Chemistry, Lviv Polytechnic National University
}

Received: February 16, 2010 / Revised: March 15, 2010 / Accepted: April 24, 2010

(C) Reutskyy V., Ivashchuk O., Mudryy S., Mitina N., 2010

\begin{abstract}
Influence of individual compounds with innercomplex properties in the liquid phase cyclohexane oxidation process has been considered.
\end{abstract}

Keywords: cyclohexane, oxidation, catalysis, chelates, complex compounds.

\section{Introduction}

The main trend of cyclohexane and other hydrocarbons oxidation intensification in the liquid phase and improvement of their technical and economical indexes is creation of complex catalytic systems primarily those containing organic additives of different nature [1-3]. The common feature of these agents is their ability to enter into the ligand environment of catalyst central atom - metal of variable valency. That is why in literature a positive effect of catalytic systems containing organic additives of different nature is attributed to the formation of complexes or ionic associates between molecules of catalyst and organic agent - intra- and intermolecular bonds coordination of electron-acceptor cobalt atom and cocatalyst functional groups [1].

Catalytic systems described in literature allow to improve base products selectivity of cyclohexane oxidation process at the same conversion level as in the industrial processes or even higher [1-3]. Also during the cyclohexane oxidation in the presence of these catalytic systems change of correlation between base products (cyclohexanol and cyclohexanone, COL/CON) is observed. However, due to the presence of two components in the catalytic system, ligand environment of catalyst central atom is likely to change. Such unstable composition of the catalytic complex can lead to decrease of its efficiency.

In view of the above stated it is considered appropriate to investigate the influence of individual cyclohexane oxidation catalysts that have innercomplex compounds properties and probably have related properties to the aforesaid catalytic systems. For this purpose, influence of cobalt chelate compounds (complexes containing central ion of metal - cobalt, which is a part of the industrial catalyst and the organic ligands coordinated around it) on cyclohexane oxidation was researched (Figs. 1 and 2).

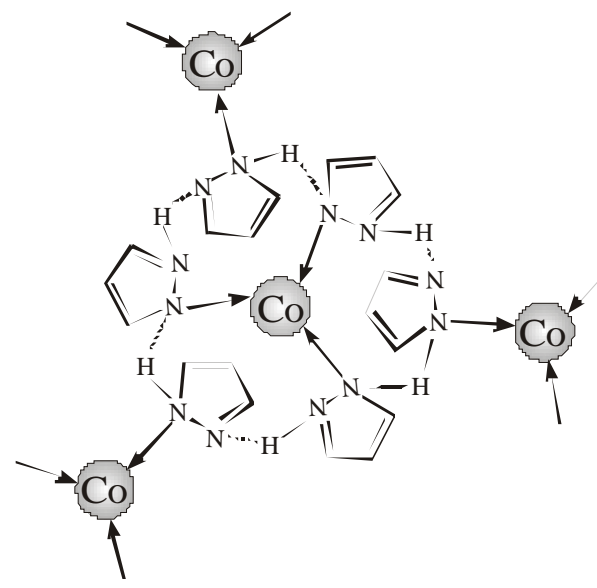

Fig. 1. Cobalt chelate (CH1): cobalt pyrazole polychelate<smiles>CCOC(=O)C=CCC=CC(C)(C)OOC(C)(C)C</smiles>

Fig. 2. Cobalt chelate $(\mathrm{CH} 2)$ : cobalt oligoperoxide complex

Ligand: copolymer vinyl acetate (VA), 5-tret-butyl hydroperoxy)-5-methyl-1-hexen-3-in (VEP), butyl acrylate (BA), dimethylamine ethyl acrylate (DEA) (chelate Co, ligand: VA-VEP-BA-DEA (2:3:5:2)) 


\section{Experimental}

Cyclohexane oxidation in the presence of cobalt chelates at the temperature of $418 \mathrm{~K}$ and pressure of 1.0 MPa was studied. These conditions were similar to the industrial process of cyclohexane oxidation. Technical oxygen as oxidant was used.

Research of cyclohexane oxidation was conducted at the pilot autoclave plant with electric heating jacket reactor. Stable temperature was maintained by silicon oil in the reactor shell (Fig. 3).

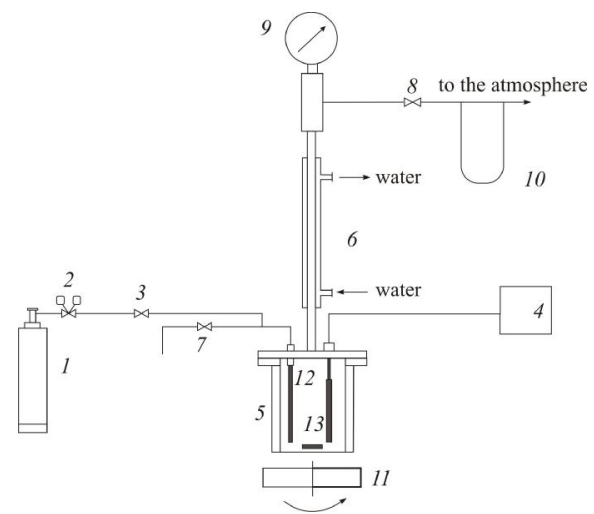

Fig. 3. Autoclave plant for cyclohexane oxidation: oxygen cylinder (1); reducer (2); valves $(3,7,8)$; control equipment (4), reactor for cyclohexane oxidation (5); shell-and-tube heat exchanger (6); pressure gauge (9); differential pressure gauge for the oxygen cost measuring (10); magnetic mixer (11); capillary for oxygen feed (12) and thermocouple (13)
For the purpose of samples homogenization and dissolution of adipic acid formed in large quantity at cyclohexane conversion increasing containers with isopropyl alcohol were used for the samples storage. Products composition was determined by titrimetric and chromatographic analyses [4].

\section{Results and Discussion}

As is known, effective catalytic systems for cyclohexane oxidation process, whose action is associated with formation of intermediate complexes or ionic associates in reactionary environment, are solutions of cobalt naphthenate (CoNph) and nonionic surfactants in cyclohexanone [2].

Experimental data were compared with those indicators that have been achieved for cyclohexane oxidation in the presence of individual cobalt naphthenate and solution of CoNph and polyethylene glycol with average molecular weight 2000 (PEG2000) in cyclohexanone (CoNph + PEG2000 + CON) for similar conditions (Table 1).

The main process parameters at different conversions of cyclohexane allow to obtain a general idea of the dynamics of the process at the starting point and during the oxidation reaction (Table 1). Cyclohexane conversion value $X=2 \%$ is a critical point to observe practical effect of the catalyst usage; $X=4 \%$ is close to the production process parameters.

Table 1

Cyclohexane oxidation parameters at conversion values $X=2 \%, X=4 \%$

\begin{tabular}{|c|c|c|c|c|c|c|c|}
\hline \multicolumn{8}{|c|}{ Conversion $\mathrm{X} \sim 2 \%$} \\
\hline Catalyst & $\underset{\%}{\mathrm{~S}\left(\mathrm{CHP}^{1}\right),}$ & $\begin{array}{c}\mathrm{S}\left(\mathrm{A}^{2}\right), \\
\%\end{array}$ & $\mathrm{~S}\left(\mathrm{ET}^{3}\right), \%$ & $\begin{array}{c}\mathrm{S}(\mathrm{COL}), \\
\%\end{array}$ & $\begin{array}{c}\mathrm{S}(\mathrm{CON}), \\
\%\end{array}$ & $\begin{array}{c}\mathrm{S}\left(\mathrm{BP}^{4}\right), \\
\%\end{array}$ & $\frac{\mathrm{C}(\mathrm{COL})}{\mathrm{C}(\mathrm{CON})}$ \\
\hline CoNph & 18.53 & 12.48 & 11.58 & 40.72 & 16.69 & 79.80 & 2.44 \\
\hline $\begin{array}{c}\text { CoNph + PEG2000 + } \\
\text { CON }\end{array}$ & 3.91 & 7.21 & 4.12 & 40.36 & 44.40 & 90.05 & 0.91 \\
\hline $\mathrm{CH} 1$ & 4.35 & 2.21 & 6.01 & 59.51 & 27.92 & 93.78 & 2.13 \\
\hline $\mathrm{CH} 2$ & 2.13 & 4.85 & 3.28 & 62.48 & 27.26 & 91.50 & 2.29 \\
\hline \multicolumn{8}{|c|}{ Conversion $\mathrm{X} \sim 4 \%$} \\
\hline Catalyst & $\begin{array}{c}\mathrm{S}\left(\mathrm{CHP}^{1}\right), \\
\%\end{array}$ & $\begin{array}{c}\mathrm{S}\left(\mathrm{A}^{2}\right), \\
\%\end{array}$ & $\mathrm{~S}\left(\mathrm{ET}^{3}\right), \%$ & $\begin{array}{c}\mathrm{S}(\mathrm{COL}), \\
\%\end{array}$ & $\begin{array}{c}\mathrm{S}(\mathrm{CON}), \\
\%\end{array}$ & $\begin{array}{c}\mathrm{S}\left(\mathrm{BP}^{4}\right), \\
\%\end{array}$ & $\frac{\mathrm{C}(\mathrm{COL})}{\mathrm{C}(\mathrm{CON})}$ \\
\hline CoNph & 5.11 & 18.58 & 22.08 & 36.91 & 17.32 & 73.30 & 2.13 \\
\hline $\begin{array}{c}\text { CoNph + PEG2000 + } \\
\text { CON }\end{array}$ & 0.65 & 8.61 & 5.13 & 40.17 & 45.43 & 87.97 & 0.88 \\
\hline $\mathrm{CH} 1$ & 0.99 & 4.10 & 5.39 & 58.96 & 30.57 & 92.31 & 1.93 \\
\hline $\mathrm{CH} 2$ & 1.54 & 4.58 & 4.68 & 53.60 & 35.60 & 92.30 & 1.51 \\
\hline
\end{tabular}

Note: ${ }^{1}$ cyclohexyl hydroperoxide; ${ }^{2}$ acids, ${ }^{3}$ ethers, ${ }^{4}$ base products 
At cyclohexane conversion $X \sim 2 \%$ the amount of the base products was higher in the presence of the investigated single catalysts as compared to individual CoNph (Fig. 4). This is the evidence of significantly lower rate of accumulation of by-products, which in turn can be associated with different nature of modifying compounds (Table 1).

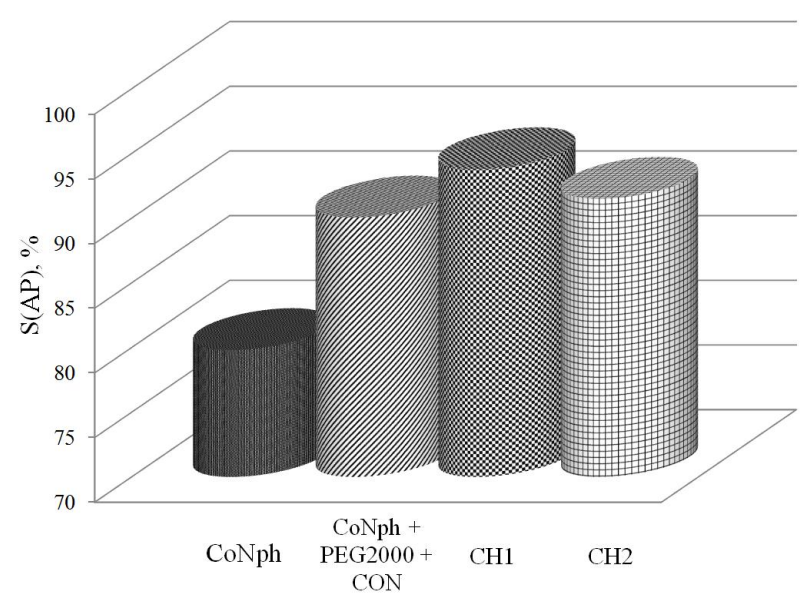

Fig. 4. Base products selectivity at conversion $X \sim 2 \%$

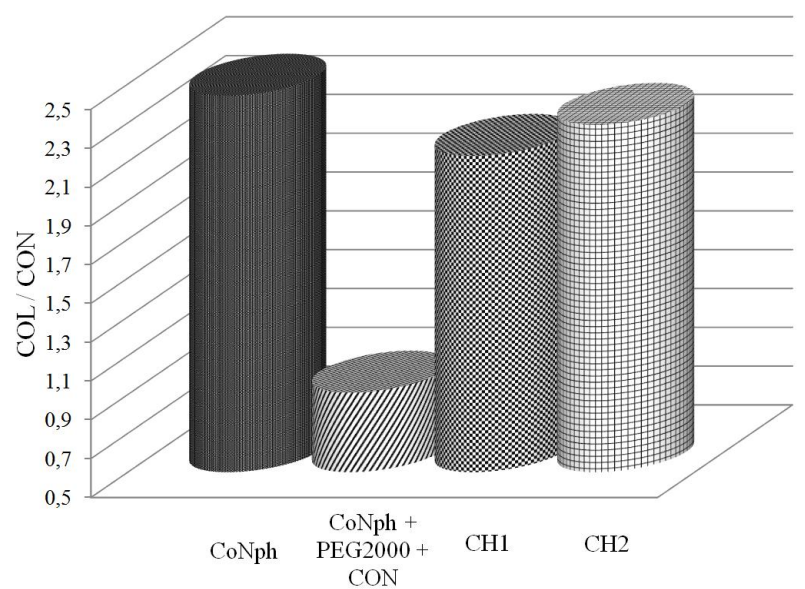

Fig. 5. Base products $\mathrm{COL} / \mathrm{CON}$ ratio at conversion $\mathrm{X} \sim 2 \%$

The highest base products (BP) selectivity at $\mathrm{X}=2 \%$ is observed in the presence of $\sim 93.8 \% \mathrm{CH} 1$, which is $14 \%$ higher in comparison with the industrial catalyst $\mathrm{CoNph}$. The COL/CON ratio remained almost unchanged (Fig. 5). The number of acids in the reactionary mixture remained approximately $10 \%$ lower. Chelate $\mathrm{CH} 2$ displayed a similar effectiveness - the BP selectivity was close to $\mathrm{CH} 1(91.5 \%)$.

The tendencies of target and by-products of cyclohexane oxidation accumulation in the presence of cobalt chelates and catalytic solution [CoNph + PEG2000+ $+\mathrm{CON}$ ] are similar (Table 1 ). More CON in reactionary environment can be explained by the initial introduction of insignificant number of $\mathrm{CON}$ together with the catalytic solution.

The data obtained at cyclohexane conversion close to industrial indices are very important (Figs. 6 and 7). They allow to predict the efficiency of catalytic systems for production conditions. The base products selectivity is above $90 \%$ in the presence of $\mathrm{CH} 1$ and $\mathrm{CH} 2$ (Table 1).

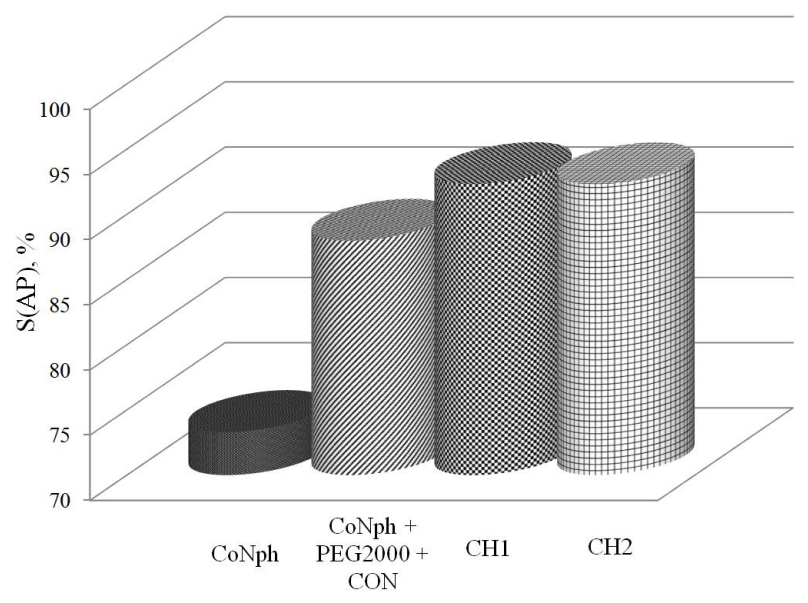

Fig. 6. Base products selectivity at conversion $X \sim 4 \%$

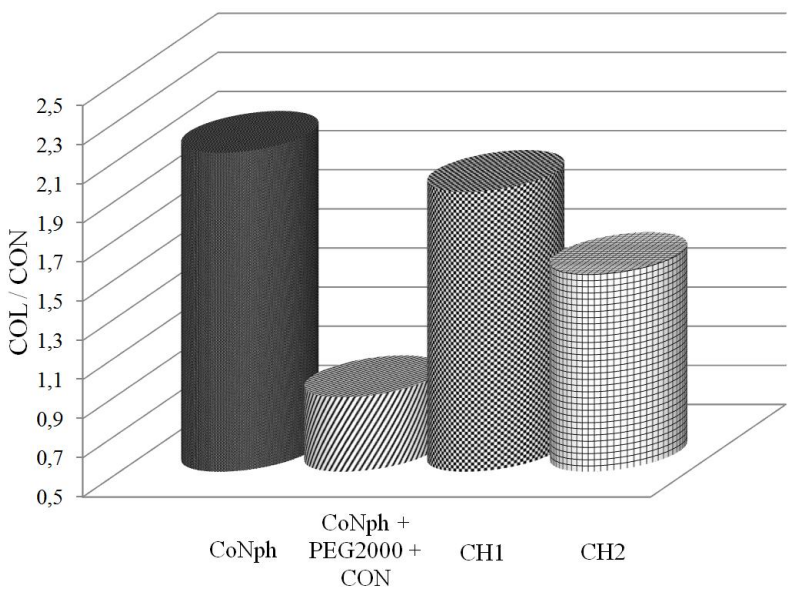

Fig. 7. Base products $\mathrm{COL} / \mathrm{CON}$ ratio at conversion $\mathrm{X} \sim 4 \%$

Accumulation of cyclohexanone in the presence of $\mathrm{CH} 2$ is not pronounced (Table 1, Fig. 7). The results show decreasing contents of base products in the presence of CoNph (by $6.5 \%$ ) and [CoNph + PEG2000 + CON] (by $2 \%$ ) at higher process conversion, while it is almost unchanged in the presence of $\mathrm{CH} 1$ and $\mathrm{CH} 2$. Oxidation products accumulation in the presence of cobalt chelates and catalytic solution $[\mathrm{CoNph}+\mathrm{PEG} 2000+\mathrm{CON}]$ have similar character (Table 1).

$\mathrm{COL} / \mathrm{CON}$ ratio is lower at $\mathrm{X}=4 \%$ in comparison with $X=2 \%$ for all studied catalysts (Figs. 5 and 7). It should be noted that the content of acids was almost unchanged in the presence of $\mathrm{CH} 1$ and $\mathrm{CH} 2$, but increased 
by $6 \%$ in the presence of CoNph (Table 1). The obtained results showed the in the presence of cobalt chelates it is possible to increase cyclohexane conversion and to obtain the same content of reactionary mixture as with $\mathrm{CoNph}$ catalyst at lower cyclohexane conversions.

\section{Conclusions}

Therefore, usage of the catalytic solution [CoNph+ + PEG2000 + CON] and cobalt chelates leads to decrease of by-products selectivity and increase of base products selectivity values as well as accumulation of cyclohexanone in the reactionary mixture.

Thus, the influence of individual compounds with innercomplex properties as cyclohexane oxidation liquid phase catalysts correlates with the research results of complex cobalt naphthenate based catalytic solutions. Cobalt chelates promote accumulation of cyclohexanone in the reactionary mixture and allow to obtain higher BP selectivity $(\sim 92 \%)$ at industrial cyclohexane conversion values. However, these results are far from ideal.

The obtained experimental data confirm the assumption about the efficiency of individual innercomplex compounds utilization in the process of cyclohexane oxidation and allow to make the following step in finding and creating of an efficient catalytic system that would enable predicting of quantitative and qualitative composition of the products of cyclohexane oxidation.

\section{References}

[1] Mel'nyk Yu., Reutskyy V. and Ivashchuk O.: Khimichna Promyslovist' Ukrainy, 2007, 2, 11.

[2] Ivashchuk O., Mudryy S. and Reutskyy V.: Voprosy Khimii i Khimich. Technol., 2008, 1, 63.

[3] Ivashchuk O. and Reutskyy V.: Chem. \& Chem. Technol., $2008,2,85$.

[4] Ivashchuk O.: PhD thesis, Lviv 2007.

\section{ОКИСНЕННЯЦИКЛОГЕКСАНУ У ПРИСУТНОСТІ ХЕЛАТНИХ СПОЛУК КОБАЛЬТУ}

Анотація. У статті розглянуто вплив індивідуальних сполук з внутрішньокомплексними властивостями на процес рідиннофазного окиснення циклогексану.

Ключові слова: ицклогексан, окиснення, каталіз, хелати, комплексні сполуки. 